\title{
The synergistic role of embeddedness and capabilities in industrial symbiosis: illustration based upon 12 years of experiences in the Rotterdam Harbour and Industry Complex
}

\author{
Leo W. Baas* \\ Erasmus Centre for Sustainability and Management \\ Erasmus University \\ P.O. Box 1738, 3000 DR Rotterdam, The Netherlands \\ E-mail: baas@fsw.eur.nl \\ *Corresponding author

\section{Don Huisingh} \\ Institute for a Secure and Sustainable Environment \\ University of Tennessee \\ 311 Conference Center Building \\ Knoxville, TN 37996-4314, USA \\ and \\ Erasmus Centre for Sustainability and Management \\ Erasmus University \\ P.O. Box 1738, 3000 DR Rotterdam, The Netherlands \\ E-mail: DonaldHuisingh@ln.utk.edu
}

\begin{abstract}
Industrial Ecology (IE) is a known concept worldwide; however, its dissemination is not an easy process. Industrial routines are embedded in unsustainable practices that are difficult to change. The complexity and uncertainties of new concepts are often approached with ignorance and misperception. Nevertheless, the integration of economic, environmental and social dimensions in industrial activities is increasingly perceived as a necessary condition for a sustainable society. The paper reflects on the theories of embeddedness, capabilities and transformation to practical experiences of Industrial Symbiosis (IS) in the Rotterdam Harbour and Industry Complex (HIC).
\end{abstract}

Keywords: industrial ecology; social sciences; embeddedness; capabilities; transformation; Rotterdam harbour and industry area; Happy Shrimp Farm; HSF; waste heat.

Reference to this paper should be made as follows: Baas, L.W. and Huisingh, D. (2008) 'The synergistic role of embeddedness and capabilities in industrial symbiosis: illustration based upon 12 years of experiences in the Rotterdam Harbour and Industry Complex', Progress in Industrial Ecology - An International Journal, Vol. 5, Nos. 5/6, pp.399-421.

Biographical notes: Leo Baas has a Master of Science in Sociology of Industry and Business Management with a specialisation in Environmental Sciences and $\mathrm{a} \mathrm{PhD}$ in Social Sciences on the subject of the dynamics of the 
introduction and dissemination of the new concepts of Cleaner Production and Industrial Ecology in industrial practice. At Erasmus University, he is the Director of the International Off-Campus PhD Programme on Cleaner Production, Cleaner Products, Industrial Ecology and Sustainability and he coordinates the Social Science Track of the Inter-University MSc in Industrial Ecology Programme (in cooperation with the Delft University of Technology and Leiden University). He is an Advisor of the UNEP/UNIDO National Cleaner Production Centres Programme and a member of UNEP's High Level Expert Forum on Sustainable Consumption and Production.

Donald Huisingh is a Professor of Sustainability at the Institute for a Secure and Sustainable Environment of the University of Tennessee, Knoxville, TN, USA. He is a part-time Professor of Cleaner Production at the International Institute for Industrial Environmental Economics, Lund University, Lund, Sweden. He is a part-time Professor of Cleaner Production at Erasmus University in Rotterdam, the Netherlands. He is the Founder and Editor-in-Chief of Elsevier's Journal of Cleaner Production. This journal is now in its 17th year. He received his BS (Summa Cum Laude) in Science Specialisation from the University of Minnesota in 1961. He received his PhD with Outstanding Distinction in Biochemistry and Plant Pathology from the University of Wisconsin in 1965 . He is the author or co-author of more than 300 publications, reports and videos.

\section{Introduction}

Industrial Ecology (IE), which is sometimes described as: "an integrated system, in which the consumption of energy and materials is optimized and the effluents of one process serve as the raw material(s) or energy for another process" (Frosch and Gallopoulos, 1989), is an increasingly well-known concept, worldwide. The IE concept was introduced to industrial leaders as a prevention-oriented paradigm for achieving cleaner industry and more sustainable communities. The Industrial Symbiosis (IS) approach in Kalundborg, Denmark, is often used as an illustration of developing linkages of utilities and waste applications among companies in an industry complex (Gertler, 1995). In spite of that and other successes, the widespread adoption and implementation of the concepts and practices related to IE has been found to be a difficult and slow process.

The United Nations argue that increasing water problems worldwide are caused by industrial procedures and routines that are embedded in unsustainable practices. The complexity and uncertainties of testing and implementing new concepts, procedures and technologies - for instance sustainable production and consumption in the plan of implementation of the Johannesburg Summit in 2002 - are often approached from a perspective of scepticism, ignorance, misperception and fear of making any changes. (Commission on Sustainable Development, 2005)

In this context it is increasingly being found that previously, there had been too much emphasis upon the technological and mechanical dimensions of change and far too little emphasis upon understanding and working with the nontechnical dimensions. Therefore, better success is being achieved by integration of the economic, environmental and social dimensions into the IE activities. In fact this integration is being documented to be an essential condition for making progress toward a more sustainable society (Baas, 2005). 


\section{Eco-industrial parks and complexity}

The complex system of eco-industrial parks involving different companies and actors (including their different activities and targets) that is required for the existence and development of IE in a region is an important, but time-consuming structure (Baas, 2005). In the last decade, global trends in environmentally related issues within Multinational Corporations (MNCs) have revealed that more and more of them are gradually incorporating different dimensions into their policies and operational strategies. The progression is:

1 gradually more and more companies have and are incorporating concepts of environmental management (ecology)

2 then some companies incorporated concepts of cleaner production (ecology, economy)

3 others incorporated IE (ecology, economy)

4 finally, some are now incorporating 'Corporate Social Responsibility' (CSR) into their approaches (ecology, economy, social aspects).

Considering the practical experiences of the introduction and dissemination of IE from a sustainability perspective, the concept was initially focused upon addressing materials and energy flows as results from human activities. The authors of this paper are convinced that more effective and efficient progress with IE will be made if all IE promoters work with the framework of the essentiality of also integrating the following three social science dimensions into their IE efforts:

1 IE activities do not occur in a vacuum, they are embedded, that is, they are shaped by the context in which they occur. Economic relations between individuals or firms are embedded in actual social networks and do not exist in an abstract idealised market according to Granovetter (1985).

2 In mapping different approaches in sustainable development, socio-economic well-being and equality issues require attitudinal and procedural changes based on increasing socio-environmental concerns, within a status quo, reform, or transformation context (Hopwood et al., 2005).

3 Consequently, new types of capabilities that are needed for supporting changes beyond the status quo situation, are required (Baas and Boons, 2007).

The interlinkages of the physical, environmental and social science dimensions will be presented based upon ongoing developments in the Rotterdam Harbour and its large Industry Complex (HIC) that was initiated in 1994.

Two illustrative cases will be highlighted:

1 the process of the start-up of the utilisation of waste heat for district heating of 3000 houses in February 2007 and leading to a total number of 500000 houses in 2020

2 the production of king-size shrimps in the Happy Shrimp Farm (HSF) on an IE basis since March 2007, illustrate the need for longer-term sustainability approaches. 
Experiences in IE projects show that an open, reflective and ongoing dialogue must be designed to develop trust and transparency to ensure real involvement of diverse stakeholders in charting the future of their organisations and regions as part of the transition to sustainable societies.

\section{Overview of organisational developments in the Rotterdam HIC}

The Rotterdam Harbour and Industry Complex (HIC) ${ }^{1}$ has been an environmental sanitation area in the period 1968-1998. The regional Environmental Protection Agency (EPA) and Water Authority regulate all companies in the area. Many, but not all, ${ }^{2}$ companies are involved in different covenants, ${ }^{3}$ concerning environmental performance targets, such as covenants on the reduction of hydrocarbons, the Chlorine Fluor Carbon reduction programme, the implementation of environmental management systems, and the four-year environmental management plan of a company. The INdustrial EcoSystem (INES) project in the Rotterdam harbour industrial area started with the participation of 69 industrial firms in 1994 (Boons and Baas, 1995). The project was initiated by an industrial association Deltalinqs, active in the joint interests of industrial companies in the Europoort/Botlek harbour and industry area near Rotterdam.

Originally, the Deltalinqs approach to environmental problems was very defensive. Later, a more constructive attitude was developed through the stimulation of environmental management in companies. Subsidies for the development and implementation of environmental management systems were used for the supervision of this implementation process in the period 1991-1994. The industrial association stimulated the acquisition of knowledge about environmental management and the feeling of responsibility of the companies through a communication structure involving meetings of environmental coordinators in six similar sectors of industry.

\section{Phase 1 - The development of environmental management systems}

Following the national trend of self regulation, Deltalinqs in 1989 started to develop an approach to promote environmental management systems in 70 member companies. During the period 1991-1994 it stimulated the companies' own responsibility through separate meeting groups for six branches of industry that meet each other quarterly. Facilitated by a consultant, companies exchanged information and experiences on the implementation of environmental management systems. In a coordinating group, experiences were exchanged among these groups. This structure was evaluated positively by the participating environmental coordinators of the firms. Deltalinqs started to search for funds, which led to the start of the INES programme in 1994.

Phase 2 - INES (1994-1997)

INES was initiated by Deltalinqs in April 1994 by means of an awareness-raising and educational workshop for environmental managers/coordinators as well as local plant managers of member companies. At the workshop, two representatives of the Kalundborg IS project presented data on IE. During their orientation visit in the area, they saw many challenges for IE approaches. Although several bilateral arrangements already existed, the systematic holistic search for the possibilities of sharing resources across 
firms - symbiotic linkages to use the language of IE - was new in the region. Also, cooperation between industry and universities in the development and the experiment of applied science for environmental purposes was a new experience.

A second workshop was organised in September 1994, and aimed at training environmental coordinators. In order to assess their needs, a survey was held which gave a general image of the 69 companies participating in INES. At the workshop, participants expressed the desire to draw up a project statement. They formulated the INES Declaration, which was never formalised but nevertheless expresses the view of environmental coordinators/managers. It captures the development of companies from environmental management systems towards an approach that considers the life cycle of their products (thus including the product chain) as well as the need to look for possible exchanges within the region (regional IE).

Following the workshop, the resources, products and waste streams of companies were assessed in order to define possible projects. A pre-feasibility study was done on all 15 ideas by researchers of the participating universities. Three projects were selected for further feasibility studies: joint systems for compressed air (Silvester, 1997), waste water circulation, and a bio-sludge reduction system.

\section{Phase 3 - INES-Mainport}

In 1998, the results from the INES programme were evaluated by the Board of Deltalinqs, which took time given their meeting only twice every year (Baas, 2001). Deltalinqs learned from the first INES programme (Baas, 2001) and used this period to acquire new funding for a second INES programme, called the INES Mainport project 1999-2002.

The INES Mainport project was a four-year programme focused on initiating and supporting IS initiatives, coordinated again by Deltalinqs. The INES Mainport project (1999-2002) was developed within the framework of the ROM-Rijnmond Covenant. This covenant was signed on 9 December 1993 by national and regional governments, and industry to develop and implement a vision for 2010 on physical planning and environmental issues in the Rijnmond region. Its aim was to provide a responsible balance between the strengthening of the Mainport Rotterdam and the improvement of living conditions. This covenant had industry as one of its target groups, and the work of Deltalinqs was seen as a suitable implementation of this. Thus, ROM-Rijnmond provided funding, while industry supported the project with time of their employees.

The INES Mainport 1999-2002 project took the feasibility studies of the INES 1994-1997 programme and focussed on the following themes:

- water

- $\mathrm{CO}_{2} /$ energy

- utility sharing

- rest products/waste management

- soil

- logistics. 
At the same time, a more strategic process was initiated. The project initiated a strategic decision-making platform, in which the societal actors from industry, government, EPAs, an environmental advocacy association and a university were involved. The platform did meet occasionally, but was not actively approached to bring in new incentives. Members saw themselves as part of a sounding board, and were willing to think along during meetings with project reports as they were presented by Deltalinqs.

\section{Phase 4 - Inclusion in Sustainable Rijnmond}

Starting at 1 January 2003, the IE programmes were included in the Sustainable Rijnmond and the Energy 2010 programme under the label of R3: Sustainable Enterprises in the Rotterdam HIC under the umbrella of the ROM-Rijnmond programme. Industry representatives are members of the different working groups. It can be observed that on the whole the initial institutional framework of the ROM-Rijnmond programme was traditional. In the period until 2003, no new actors at higher levels became involved.

The initial INES programme had also a conservative approach, in which stakeholders were kept at a distance. The INES Mainport Rotterdam project had the potential of constituting a new step in IE. Although in the INES Mainport project the economy dominated the bottom line, space was created for new activities such as the establishment of an intermediary organisation for the management of the project, new actors from the highest levels of industry, government, academia and NGOs, and the start of a dialogue about regional developments in a sustainability perspective. Although the INES Mainport project was explored under the umbrella of the ROM-Rijnmond project, it was hardly known to ROM-Rijnmond management (Baas, 2002).

Under the umbrella of the ROM-Rijnmond programme, a new project in addition to the preceding ones started under the name of R3: Sustainable Enterprises in the Rotterdam HIC. This project - which includes a strategic discussion platform made up of relevant stakeholders - was intended to be part of the driving mechanisms towards a sustainable region. In 2003, it presented its 45 page vision document $T o$ C or not to $C$ (ROM-Rijnmond, 2003), based on the concept of transitions, a then emerging theme in the national environmental policy agenda. The vision was summarised in the following statement:
"A world striving towards lowering carbon-intensity of the economy provides an attractive perspective for industrial centres that are able to process carbon related streams in a highly efficient, clean, and sustainable way. Rotterdam harbour is ideally suited to be such a centre. It has the ambition to be in 2020 the preferred location in Europe for the haulage and processing of carbon-related fuels and raw materials. It can only make this ambition a reality by being a trendsetter in economically feasible reductions of $\mathrm{CO}_{2}$-emissions related to these activities, and by acting as a field of experimentation for innovations on themes such as clean fossil fuels, clean energy carriers such as hydrogen, syngaz, heat, electricity and biomass as a gateway to a carbon-extensive future."

The programme runs for the period 2003-2010 and is led up by a small ROM-Rijnmond staff bureau as management for a strategic platform that involves representatives of the Ministries of Economics and Environment, the province of Zuid-Holland, the Development Board of Rotterdam, the Port Authority, the industry association Deltalinqs, 
a plant manager, the national Sustainable Mobility Programme manager, representatives of the Universities of Delft and Rotterdam and the representative of an environmental advocacy organisation. The strategic platform functions as stimulator and sustainability conscience of all involved stakeholders in these Rotterdam Energy Port developments. The members of the strategic platform also share the reflective learning processes from projects within and around their own organisations as is shown in the following Figure 1 (Baas, 2005):

Figure 1 Reflective learning from performing projects to system innovations: the transition towards sustainability

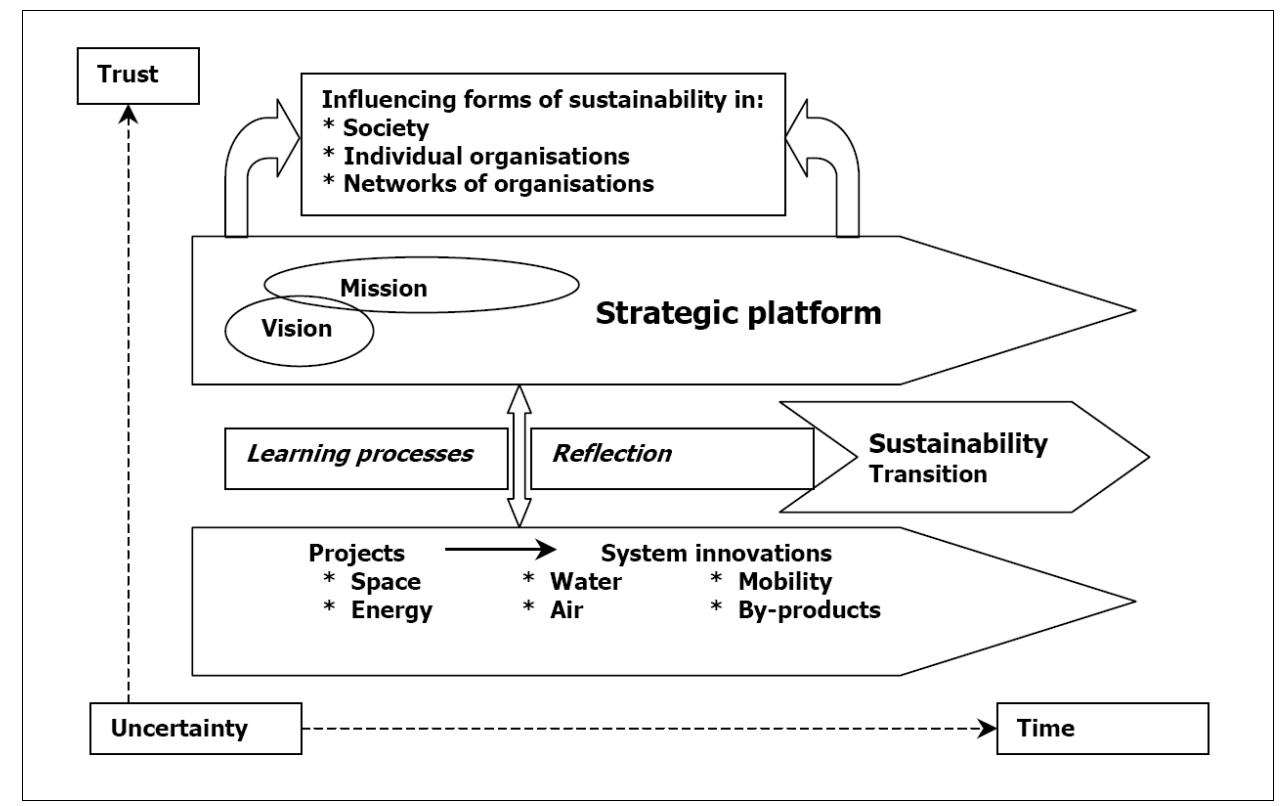

\section{Two illustrative industrial symbiosis projects in Rotterdam}

The projects described in this section are the results of continuous programmes during more than a decade:

- INES Programme 1994-1997

- INES Mainport Programme 1999-2002

- R3: Sustainable Enterprises in the Rotterdam HIC 2003-2010.

The Board of Deltalinqs evaluated and reflexively learned from the INES Project in 1998, leading to the INES Mainport Project starting in 1999 (Baas, 2001).

In this section, the IE application of rest-heat and $\mathrm{CO}_{2}$, and a spontaneous IE development called The Happy Shrimp Farm is described. 


\subsection{Waste heat capacity}

One of the projects in the INES programme 1994-1997 was the use of waste heat and $\mathrm{CO}_{2}$ by other companies. At the end of the INES project, the industrial association and an energy distributor jointly discussed how to utilise approximately $2200 \mathrm{MW}$ of heat that was emitted into the air. A pipeline system to connect suppliers and buyers in the industrial region was a first option for further study. It was calculated that such a pipeline system would cost $€ 112,700,000$ and would require government funding for the new infrastructure needed for energy distribution in the industrial region. This waste heat project was further elaborated in the follow-up INES Mainport project (Baas, 2005).

After it was determined that the establishment of a pipeline infrastructure for the whole area was economically not feasible, smaller scale projects were initiated in the INES Mainport project. The Utilisation of Industrial Rest Warmth project involved eight partner projects in the Botlek and Pernis industry clusters. The estimated total investment was $€ 83.6$ million. The Dutch National Project Office for $\mathrm{CO}_{2}$ reduction plans was requested to provide a 30\% subsidy in March 1998. A $27 \%$ subsidy was reserved in November 1998. A partnership of seven Deltalinqs companies tested the technical, operational and economic feasibility of the eight partners' projects during 1999. They decided to reject four projects, three for economic reasons, one on grounds of discontinuity of supply.

Table 1 Waste heat supply subprojects and the reasons for their rejection

\begin{tabular}{ll}
\hline Waste heat supply project from & Reason for rejection \\
\hline Air Products to Shell Chemistry & Economic - pay-back time is longer than 30 years \\
AVR to Dapemo & Discontinuity in steam demand of Dapemo \\
Lyondell to Climax & Economic - not feasible \\
Esso to ORC & Economic - not feasible \\
\hline
\end{tabular}

The four projects represented $63 \%$ of the estimated investments for the total of eight projects. This meant also that $63 \%$ of the subsidy was rejected. One of the two largest remaining projects was dropped because of the closure of the Kemira Agro plant in Pernis (part of Rotterdam).

At the beginning, despite the enormous waste heat surplus, nearly all managers of large plants had reasons to prefer their own facilities for economic (the costs of the required infrastructure) or strategic (the perceived loss of independence) reasons. That is why during the period 1997-2001, the waste heat supply project had to be downsized from a holistic regional approach to a number of small cluster projects. After this approach appeared to be economically unsuccessful, a feasibility study for warmth delivery through a private 'Heat Company' was performed (ROM-Rijnmond, 2003). One of the drivers of the continuing effort to implement this theme was pressure from the Water Management Authority, who made it clear that they would no longer accept emission of heat into the surface water.

At the end of the INES Mainport programme and in cooperation with ROM-Rijnmond Energy projects several new partners (housing cooperations, energy suppliers) entered the 'playing field'. They formulated the condition that decoupling of the rest industrial heat of Shell Pernis refinery (and later of Esso/Exxon and BP 
refineries) to the Rotterdam city district heating system should be economically viable and that the responsibility for the coupling between industry and city should be organised clearly. In 2002, the Rotterdam municipality decided to provide a guarantee for the extra funds that had to be invested in a heating system with temporary equipment in a new residential area nearby the Shell industrial site in Pernis (part of Rotterdam) and a safety net construction when the application of waste heat should fail. When all conditions for realisation were finally met in 2004 (including liberalisation of the Dutch energy market, and reductions of $\mathrm{CO}_{2}$ demanded by the national government as part of the Kyoto-protocol agreement), the decoupling of the $6 \mathrm{MW}$ of Shell's rest industrial heat to the city's district heating system would make the temporary equipment redundant; 3000 houses would benefit in the Hoogvliet residential area in 2007. The heat supply system is being extended to $100 \mathrm{MW}$ for the application to 50000 houses $^{4}$ and the greenhouse sector (ROM-Rijnmond, 2006). In addition, activities are set up to connect 500000 dwellings and companies in the Southern part of the province of Zuid-Holland in 2020 (ROM-Rijnmond R3, 2006). Also $\mathrm{CO}_{2}$ is part of the project; a new private company OCAP has the responsibility and owns the infrastructure for the delivery of $\mathrm{CO}_{2}$ emissions from the Shell plant in Pernis to 500 greenhouse companies at the north of Rotterdam. The $\mathrm{CO}_{2}$ (and waste heat) delivery started in July 2005. The greenhouse companies reduced 170000 tonnes of $\mathrm{CO}_{2}$ emissions through saving 95 million $\mathrm{m}^{3}$ natural gas $^{5}$ in 2007. The future waste heat infrastructure is shown in Figure 2 (the red lines are the new pipelines as common carrier; the blue lines are already existing). ${ }^{6}$

Figure 2 R3 waste heat infrastructure (see online version for colours)

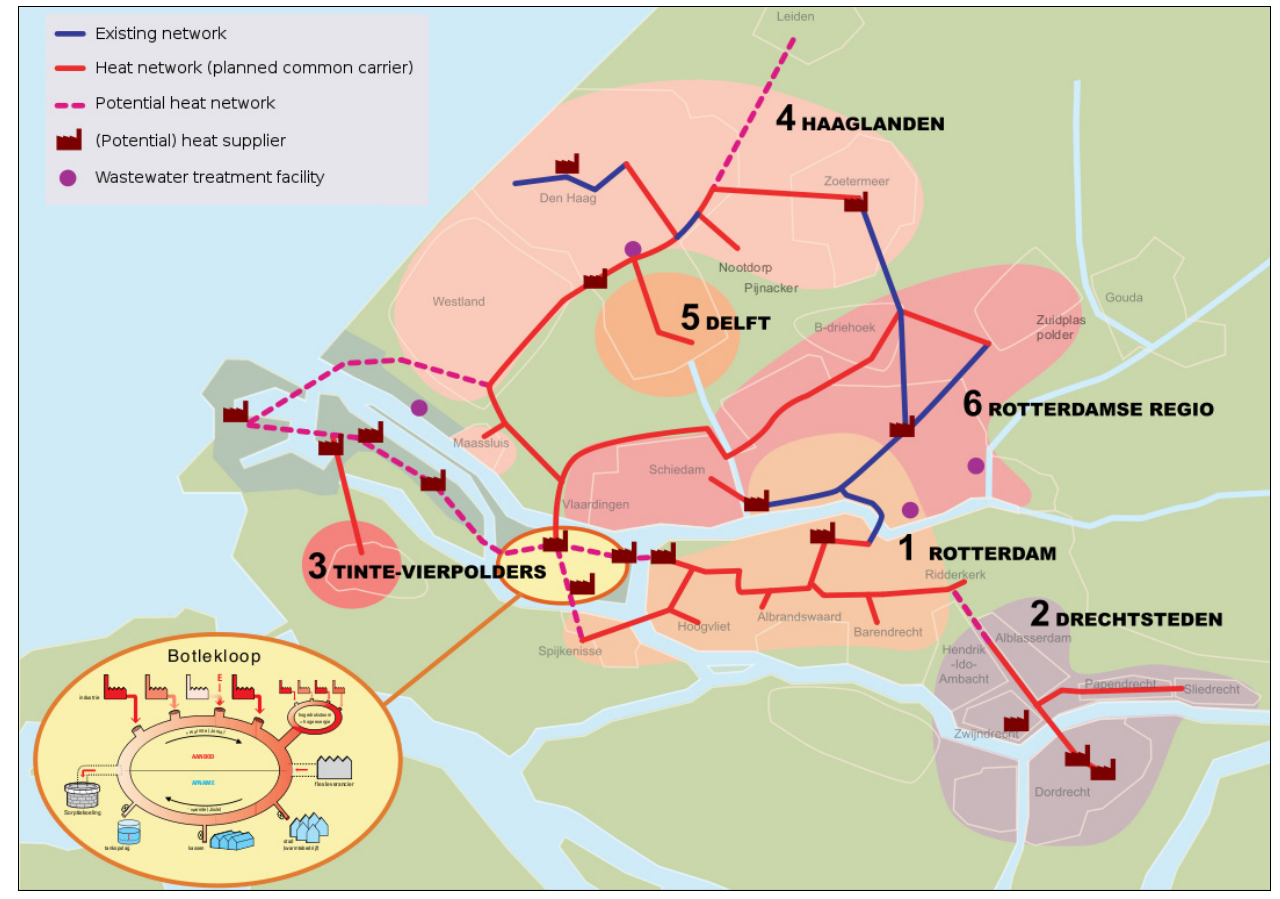




\subsection{Happy Shrimp Farm}

Two young professionals at the Rotterdam Port Authority were inspired by the INES Mainport programme and the concept of Agroparks, clusters of food production and industrial activities in an ecological symbiosis (Weterings, 2000) that was first launched by the Dutch Innovation Network in 2000. They developed the blueprint for a HSF: the idea of producing king-size shrimps in a harbour area, using waste heat from a company at the same site, should be regarded as a first step in the formation of a symbiosis of food and other industries in the Rotterdam harbour area. The start of the HSF feasibility study in 2004 was facilitated by the Port of Rotterdam. The initial setup was an incubator position by the two young professionals who could use the existing infrastructure and network of the Port of Rotterdam organisation.

The feasibility study in 2004 had a very down-to-earth entrepreneurial character, and described the benefits and risks of co-siting (two or more companies in an ecological symbiosis on one site). On the basis of criteria such as access to energy and utilities, waste treatment, efficient spatial use and last but not least, the perception of the location by the public, a choice was made for a location and a host company (the electricity plant of E-On) for the HSF. The final concept of the HSF was an integrated shrimp algae farm. The first stage was to realise a shrimp farm in the port of Rotterdam and utilise the co-site benefits. The second stage - a feasibility study to plug an algae bio-fuel reactor on to the shrimp farm - has started in September 2008. The different processes in the HSF are explained in the business plan report in 2005 (Greiner and Curtessi, 2005) that was funded by the ROM-Rijnmond programme. The HSF business plan attracted interest from many public and private parties. The HSF has certain unique selling points; the freshness/quality and the social-responsible way of farming will create its own niche market. A new production chain was set up with outlets to high quality markets. Besides that, HSF has become a symbol of affection for the IS activities in the Rotterdam HIC.

During the building of the shrimp farm, the directors started a joint-venture with another company for also growing sea vegetables in the farm, combining the shrimp breeding batch with the growth of cress on the top of the water basins, profiting from the temperature and the humidity within HSF (see Figure 3). In 2008, they started an experiment with growing orchids at a top layer in the greenhouse.

Figure 3 Sustainable farming of shrimps and cress (see online version for colours)

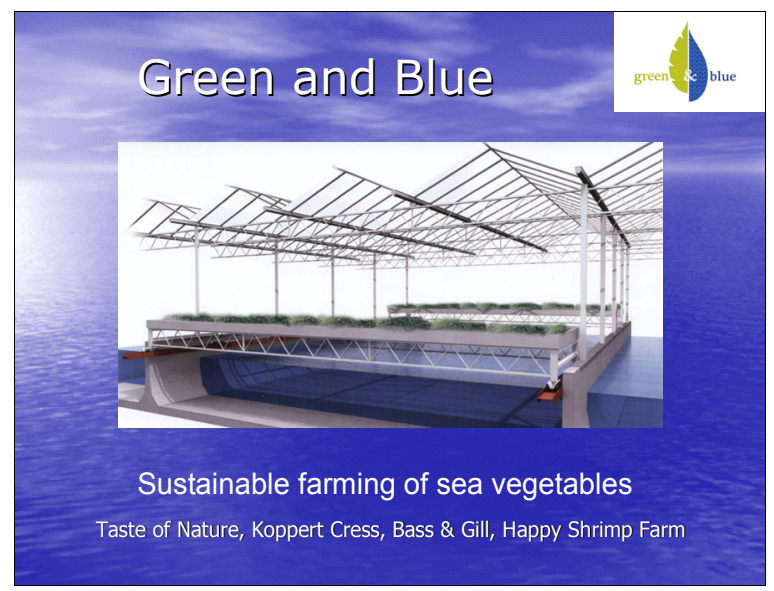


The first shrimp breeding batch started in March 2007; the first grownup shrimps have come on the market in December 2007. The E-On corporation has asked the HSF directors in 2008 to construct shrimp farms in IS with E-On electricity works in three locations in Germany and in one location in London (UK).

\section{Theoretical reflection on the introduction and dissemination of industrial ecology}

The question is whether IE/IS is part of the sustainability system. The number of companies, their diversity in size and type, and the intensity of their interactions are major variables in the system. Here the links between individual companies and the links between companies and society are to be tested according to the criteria of sustainability. This system demands a holistic approach based on new worldviews. ${ }^{7}$ The production process is an element at the level of individual companies (at the micro level) but the output of byproducts is also the function of servant of the network (Wallner, 1999) at the meso level.

In this section several social science characteristics of IE efforts are identified, among which are: embeddedness, capabilities, status quo, reform or transformation beyond the status quo.

\subsection{Types of embeddedness}

IE/IS is addressing, from a systemic perspective, material and energy streams as they result from human activities. These activities do not occur in a vacuum, they are embedded, that is, they are shaped by the social context for strategy-making in which they occur (Marx, 2004). The different dimensions can be described in terms of cognitive, structural, cultural, political, spatial and temporal embeddedness (Boons and Baas, 2006). Simsek et al. (2003) use also relational embeddedness that they describe as a reference to the quality of the relationship highlighting the effects of cohesive ties between social actors on their economic activities. They link relational embeddedness strongly to structural (Granovetter, 1992; Gnyawali and Madhavan, 2001) and cognitive embeddedness. Uzzi (1997) found in his research on embeddedness the following paradox. The stronger the embeddedness, the more difficult it will be for the counterparts to change to other partners, at least in the short run. The weaker the embeddedness, the more the relationship will have an arm's-length character.

Gnyawali and Madhavan (2001) adopt an embeddedness perspective, which suggests that competitors, far from being atomistic entities free to undertake any competitive action within their own resource constraints, are embedded in a network of relationships that influences their competitive behaviour. The structure of the network to which they belong influences the flow of assets, information and status among the network members. Network-based resource advantages vary across firms, resulting in varied levels of motivation and ability to undertake action or respond to actions of others. According to some American reports, more than $50 \%$ of new alliances are between competitors (Harbison and Pekar, 1998). Gnyawali and Madhavan (2001) detect the existence of cooperation and competition in a network, too: companies can work together by sharing 
resources and committing themselves to common task goals in certain domains; at the same time partners also compete by taking independent positions in other domains. Further, they state that the density of a network is important for facilitating flows of information and other resources, for developing trust, shared norms and common behavioural patterns as 'closed' system, and for sanctions.

This dimension is the one which has gotten most attention as organisational contribution to the field of IE. Industrial networks have been analysed, and coordination mechanisms have been discussed. However, linking these structural features to other dimensions of embeddedness remains a relatively unexplored territory.

Simsek et al. (2003) refer cognitive embeddedness to the ways in which common mental models or a shared vision among actors impact their economic activities. This is about the manner in which individuals and organisations collect and use information, and the cognitive maps they employ in making sense of their environment. Although, Simsek found that the effects of informal social networks on entrepreneurial behaviour and on innovation strategies of large companies are important, much less attention is paid to cultural embeddedness. The cultural context is rooted in historical developments and addresses the influence of collective norms and values in guiding economic behaviour, such as the shaping of preferences, and the influence of ideologies in shaping future visions. The authors believe that within the field there is a tendency to externalise normative issues, or to take normative positions for granted, both in our scientific activities and in our subject matter. However, Noorderhaven et al. (2002) argue that three organisational culture characteristics - trust, open communication and joint problem solving - are key elements for network embeddedness.

Political embeddedness is acknowledging the fact that processes of power influence economic actions. This includes the role of the state in the economic process. The role of power is hardly discussed systematically. Maybe this has to do with the fact that it is one of the more difficult concepts of sociology in terms of empirical analysis. Nevertheless, actors are not equally able to influence each other's actions and system outcomes, and this has to be taken into account. Especially the political, cognitive and cultural forms of embeddedness are determining the role of political-economic systems, ideologies and social networks in both enabling and constraining voluntary action in varied ways (Zukin and DiMaggio, 1990).

Spatial and temporal embeddedness cover the way in which geographical proximity and time influence economic action (Castells, 1996). The dimensions of space and time are implicit in many accounts of IE in peculiar, yet it is believed that they deserve explicit treatment. Physical proximity has been identified as crucial in, for instance, complex forms of learning and the building of trust. With respect to innovation processes Oerlemans et al. (2000) found that regional economic embeddedness, the strength of resource bases, and contact frequency influenced the spatial embeddedness of innovative ties with buyers/suppliers. Firms using internal and external resource bases innovate more successfully. Organisational embeddedness was strongly affected by high levels of complexity of innovative activities.

Time is important as the evolution of industrial systems typically involves long time periods: "for stakeholder dialogue and connecting different partners" (Boons, 2004). 


\subsection{An analytical framework of sustainability capabilities}

Baas and Boons (2004) have characterised the evolution of IS in the Rotterdam harbour as one developing from a collection of regional efficiency projects towards a phase of regional learning, in which the diversity of actors and issues increases, and a more strategic vision is developed. A major question is how such a development at the system level is generated through the actions of individual participants in a loosely coupled network. To provide insight into this connection, we will make use of the concept of sustainability capabilities (Baas and Boons, 2007).

The concept of sustainability capabilities is based on the resource-based view of the firm (Amit and Schoemaker, 1993; Barney, 1991; Wernerfelt, 1984). Organisational capabilities are the firm's abilities to assemble, integrate and manage resources (Russo and Fouts, 1997, p.537). Resources are distributed across firms heterogeneously, and this can explain their differential competitive advantage. Competitive advantage results from the fact that some of the resources that firms possess are rare and valuable. If, in addition, they are nonsubstitutable and nontransferable, then the competitive advantage is long-lasting (Barney, 1991). This line of reasoning can be extended to the way in which organisations deal with issues of sustainable development (for a related yet distinct approach, see Hart (1995)). It then indicates the abilities of organisations to contribute to successful clusters of sustainability.

In terms of regional clusters of sustainability, 'successful' is operationalised at the organisational level in terms of the ability of the organisation to cooperate with others, being a reflective member of a cluster, and have an ability to deal with the different values that make up sustainability: ecology, economy and social issues. The following capabilities can be identified:

- $\quad$ Technical capability is the ability to mobilise and apply knowledge related to diminishing the ecological impact of existing production and consumption processes, and the development of more sustainable products and services. The education level in general and sustainability engineering expertise in particular are import variables.

As sustainability essentially deals with the economic, social and ecological aspects of industrial activities, organisations within a cluster need to have the ability to integrate the concerns around these values (Value capability). It requires routines to integrate information and to inform decision making and action of different parts of the organisation. This is a process capability rather than a content capability, as the three aspects that constitute sustainability will be seen and valued by various cluster members in different ways. At the same time we want to include unlearning processes in learning processes within IS activities. Institutionalised routines that provide a barrier to collaborative approaches to sustainable development are questioned and shed (Unlearning Capability in Huy (2001)).

Sustainable development requires the selection of an optimal system boundary by actors when they develop goals and form clusters (Boundary Capability in Dietz (1992)). This requires the ability to look at activities in terms of the system in which they are situated, and evaluate them accordingly. Given the selection of a system boundary, actors need to be able to mobilise the players that are part of the present or envisioned future system. This can be called the actualisation of the selected system. In a regional cluster, there will be actors that do not wish to cooperate because sustainability is not their aim. 
Alternatively, leading actors in terms of sustainable development may choose not to participate in the cluster because they do not wish to share their accumulated knowledge or advantages.

A very important variable is trust. We already referred to trust as a dimension of embeddedness (Noorderhaven et al., 2002). Nooteboom (1999) analysed the development of trust capability in innovation process. The phase of exploration starts with the radical innovation of the novel practice. Then a process of trial and error must generate a phase of consolidation that becomes a dominant domain. Because this innovation process is not based on a single project, the model is fed by an internal need to cope with disintegration elements in core-business activities. Nooteboom (1999) explains that “...disintegration is dynamically efficient to generate exploration, while integration into tighter intra-firm networks is needed to achieve productive efficiency in exploitation...".

We assume the same for sustainability development in the way that it requires the development of joint values and ethics of the concept of sustainability, an adequate communication infrastructure, insight in each other's position to stimulate networks, as well as clear procedures for dealing with sensitive information. Trust that exists at the personal, organisational and inter-organisational levels, is effective in a cluster through lessening concerns about opportunistic behaviour, and a better integration of the partners.

The ability of organisations to shape and apply regulations in such a way that they contribute to the region's goals is needed within this context (Regulatory Capability).

\subsection{A sustainability transformation mode}

In mapping different approaches in sustainable development, socio-economic well-being and equality issues are requiring changes based on increasing environmental concerns, in a status quo, reform, or transformation mode (Hopwood et al., 2005). The sustainability transformation mode provides the context within which the analysis of embeddedness and capability dimensions can be analysed.

Supporters of the status quo recognise the need for change but see neither the environment nor society as facing insuperable problems. Adjustments can be made without any fundamental changes to society, means of decision making or power relations. This is the dominant view of governments and business and supporters of the status quo are most likely to work within the corridors of power talking with decision makers in government and business. Development is identified with growth and economic growth is seen as part of the solution. It is argued that business is the driver towards sustainability. Increased information, changing values, improved management techniques and new technology all operating through the market are the best means to achieve sustainable development. However, according to Senge et al. (1999): "collaboration is vital to sustain what we call profound or really deep change, because without it, organisations are just overwhelmed by the forces of the status quo".

Those who take a reform approach accept that there are mounting problems, being critical of current policies of most businesses and governments and trends within society, but do not consider that a collapse in ecological or social systems is likely or that fundamental change is necessary. They generally do not locate the root of the problem in the nature of present society, but in imbalances and a lack of knowledge and information, and they remain confident that things can and will change to address these challenges. They generally accept that large shifts in policy and lifestyle, many very profound, will be needed at some point. However it is assumed that these can be achieved over time 
within the present social and economic structures. The key is to persuade governments and international organisations, mainly by reasoned argument, to introduce the needed major reforms. They focus on technology, good science and information, modifications to the market and reform of government.

Those who adopt a transformation approach that embraces both social and environmental questions cover a range of different viewpoints although all share the view that the mounting crises in the environment and society are interconnected and that the social and environmental systems risk breakdown if radical change does not occur (George, 1999; Rees, 1995). Transformation promoters see the fundamental problems as rooted in our present society, which is based on the exploitation of most people and the environment. A transformation view of sustainable development has a strong commitment to social equity, with a view that access to livelihood, good health, resources and economic and political decision-making are connected. Transition management as narrowly related concept is described as a new governance-model based on complex systems' thinking and is aimed at facilitating and directing processes of societal change in the direction of sustainability. It is a form of participatory governance in which envisioning, scenario-development, shared agenda-setting and experimenting are basic elements. The framework is developed in an iterative way; through constant interaction between theory development and practical application in diverse social settings (Loorbach, 2007).

\section{Conclusions on the synergetic role of embeddedness and capability dimensions in relation to the sustainability transition mode in the Rotterdam HIC}

In this section we will conclude for the synergetic role of embeddedness and capability with respect to IS activities in HIC (in Section 7 we will try to link the separate conclusions). Many multinational companies have production plants in the Rotterdam HIC. There are differences in management structure in these plants, from hands-on steering by the management of a division to a footloose construction of an affiliation of an MNC. There exist large differences in targets, vision, culture, and the sense of urgency with regard to environmental and safety risks. For instance, a large corporation's subsidiary will first look inside their own group to consider $\mathrm{CO}_{2}$ emissions reduction. Another system boundary is that new company developments are generated at other corporation levels and can cross over with regional initiatives (Baas, 2005).

\subsection{Conclusions on embeddedness}

When the dimensions of sustainability embeddedness issues are applied to IE developments in the Rotterdam HIC, a special focus on the dimension of spatial and temporal embeddedness asks attention (Baas and Boons, 2007). For instance the waste heat project has a long history; it was designed as waste heat application in the HIC region in the first INES programme in 1994. Several modifications of the project - from big to small-scale application - failed. However, the challenge for the allocation of big volumes of waste heat also generated moral pressures to periodically strong attention for exploration. When the policy and economic conditions were met in 2004, 
a Heat Company was established as responsible incubator for further developments. This development was facilitated by the situation that the industrial network was broadened with other social actors such as energy suppliers and housing cooperations (relational embeddedness).

With respect to cognitive embeddedness was found that the plant managers were working at the edge of their system boundary. They had responsibility for activities within their plant (most plants in the Europoort/Botlek area are affiliations of an MNC with the headquarters outside the region and/or country) and explored their position in the IS project. This meant dealing with trust at all levels in a position where economic and organisational constraints (a lean organisation with a limited staff) and other political preferences (such as a new government-required safety organisation in 2001) were dominant.

About the aspect of characteristics of change agents (Vliet, 1998), it can be concluded that although the intermediary position of Deltalinqs did not allow the association to coerce individual members into doing certain things, the social control position was powerful. Nevertheless, some form of objective control was needed. On the one hand, environmental and economic results had to strengthen the IE projects; on the other hand, those results had to strengthen the trust of government organisations in the competence of Deltalinqs. Also, participation in medium and long-term sustainability projects showed both an increase and a decrease in commitment of different company managers. Once a vision and a mission statement were formulated in 2000, and responsibilities were settled, daily operations had priority. Deltalinqs had a strong position in the relationship with the government, but had to show that the INES Mainport Rotterdam programme would go further than a few bilateral environmental projects. That put Deltalinqs in the following position: the association stimulated a positive feeling and trust of their member companies. Deltalinqs had a low degree of behavioural control of their member companies, which increased relational risk. But Deltalinqs had a high degree of social control, which decreased performance risk.

From 2003, the staff bureau of ROM-Rijnmond developed a strong change management position by building trust between the different strategic platform members representing government, industry, expertise centres, special task forces and an environmental advocacy organisation, on the basis of reflexive learning processes of sustainability projects in the region (see Figure 1).

With respect to structural embeddedness, rules and regulation has led to a complex maze of effects that can be counterproductive for IE, such as in the case that "the waste of one company may be a resource for another" (Frosch and Gallopoulos, 1989) can be blocked by the ban of the transport of waste from one company to another.

However, it can be analysed that the industrial association Deltalinqs, the Rotterdam Port Authority, the Rotterdam Municipality and the regional EPA have been linked in various organisational frameworks for stimulating economy and better environmental performance during several decades. The position of the different stakeholders in the region has a history in dealing with one another.

In its mindset, industry has always seen environmental investments as efficiency improvements with an expected return on investment of two to three years (Baas, 1998). After environmental policy was integrated into general policy, an expected return on investment of six years became commonplace. With the liberalisation of public energy facilities - electricity and natural gas (Jong, 2006) - in the Netherlands around the turn of the century, it is the other way around. The privatised energy companies expect a lower 
rate of return on their investments than industry, but not the traditional rate of return over a period of 30 years when they were public energy companies. ${ }^{8}$ This generated a different time frame between industry and energy companies that often hindered IE initiatives in the Rijnmond area.

For the political embeddedness can be observed that after the period of a strong need for environmental regulation, the national, provincial and municipal governments facilitated many industry programmes for strengthening economic and environmental performances, for instance through the funding (partly) of the INES Programmes, and the municipal decision about the safety net for starting the waste heat infrastructure. Also the Rotterdam Climate Initiative (RCI) with the $\mathrm{CO}_{2}$ reduction target in 2020 provides the conditions for sustainability developments (RCI is one of the 40 city programmes in Clinton's Climate Initiative in the format of a renewable energy and $\mathrm{CO}_{2}$ reduction programme).

With respect to cultural embeddedness can be analysed that the IS activities are also generating market power for new production facilities. The new ARCO poly-propylene plant was constructed on the basis of utility-sharing. Also the industrial site Maasvlakte2 that will be reclaimed from the North Sea, is designed with IE principles (Schneider, 2006).

The geographical location of HIC puts extra attention on spatial embeddedment aspects. The Europoort/Botlek area is geographically not easy for IE constructions because of the ribbon-like development of the industrial area along the borders of the river Rhine for some $40 \mathrm{~km}$. This raises the question whether it is better to design smaller cluster management for water and compressed air to stimulate a bigger system.

\subsection{Conclusions on capabilities}

With this list, we can shed light on the contribution of organisations within the INES projects to the collective results generated (Baas and Boons, 2007).

The technical capability to mobilise and apply knowledge related to diminishing the ecological impact of existing production and consumption processes, and the development of more sustainable products and services is present in several organisations within the Rotterdam harbour. These include firms, but also the universities of Delft and Rotterdam that were involved during the main part of the period under study. Especially in the first phases, the applied knowledge by industry centred on end-of-pipe measures and utility sharing between firms. The organisations within the Rotterdam harbour have been able to question existing routines, and sometimes replace them by new ones that are better suited to the increasingly strategic nature of their development towards sustainability. Most important of all, the routines that lead to a focus on the individual firm have partially been unlearned. Knowledge leading to more fundamental technological innovations has not been mobilised; in this cluster this capability mainly refers to the local application of ideas created elsewhere.

However, this process was complicated by the fact that the region consists mainly of existing firms that are worldwide competitors. They held different perspectives on implementing new regional ideas, and Deltalinqs needed to develop a strategy to focus on how to break open these different perspectives. Moreover, many firms as subsidiaries of multinational companies felt the increasing pressure from their headquarters to deliver on ever stricter financial or production goals, leaving little space for experimentation with regional collaboration. 
The value capability is of major importance for members of a developing sustainable region. In the Rotterdam harbour, a gradual development of this capability can be identified. While in the first phase the economic and environmental aspects are integrated at an operational level, later phases show that more strategic integration developed. Linking of processes is an indication of this integration, as are the discussions that took place at various workshops and within the Strategic Platform.

Another indicator is the involvement of outside stakeholders. As they express different perspectives on the balance between sustainability values, their involvement is crucial. In the case of Deltalinqs, it is clear that it increasingly saw the need to involve a more diverse set of stakeholders, which resulted in the start of a dialogue about regional developments based on a sustainability perspective (for instance for the application of waste heat). In this phase, it was still necessary to devote human energy to convincing the plant management of companies of the usefulness of this approach. This indicates that at the level of individual companies, value integration is still desired.

The boundary capability is indicated mainly by the extent to which regional participants are able to reflect upon the boundary of the system which they intend to make more sustainable. Drawing this boundary is difficult, and may require modification over time. In the Rotterdam harbour, a complicating factor comes up regularly: firms are tied up in relationships that cut across the regional boundary: they are often part of a multinational firm, and/or global product chains. Developing the regional cluster goes against the importance that is given to these relationships. This was an issue that was brought up several times in workshops and Deltalinqs meetings, showing the existence of this capability beyond the regional level.

More generally, the system boundary was enlarged in later phases to include more stakeholders. While this was to some extent the outcome of the vision of the Deltalinqs project leader, it also has to do with the linkage of the project to ROM-Rijnmond, which merger took place for funding reasons. Such as is the case with spatial embeddedness, it became apparent that the geographically ribbon-like evolutionary course of the HIC region was not easy for IE systems connecting all companies.

The actualisation capability refers to the mobilisation of relevant players in the system, and make them part of the region. The strategic level in the Rotterdam HIC has developed over the years. It has grown from a small group of committed company representatives responsible for environmental affairs, to a larger group where general managers of large firms as well as public officials have become more active over the years in participating in the creation of a vision and strategic discussions. The broadening of scope thus has been paralleled by a broadening of the group of actors involved. This is partly an effect of their personal commitment to solving ecological issues. At this level, actualisation is a result of personal networks, and is less a capability of an organisation than it is the quality of project leaders and leading participants in the cluster.

Organisations in the Rotterdam HIC have over time developed the capability to trust other organisations in the region. Starting with win-win type of INES projects in Phases 2 and 3 (where benefits for all actors involved assures cooperation), organisations in the region have developed the ability to participate in participative, integrative strategy development. Thus, trust has first of all been built up in the sector organised communication networks for environmental management (Phase 1). Environmental coordinators have, through experience, learned that they share the intention and commitment for a good environmental performance. This has provided a basis for developing inter-organisational projects that would not have been possible 
without trust. It has facilitated access to important resources and information. Tapping into the competitively valuable assets within a region requires personal relationships, face-to-face contact, a sense of common interest and 'insider' status. Deltalinqs and the strategic decision-making platform have facilitated the building and maintenance of this level of trust, also in the relationship with regulators in Phase 3. The high-level representatives of an array of organisations in the Strategic Platform in Phase 4 strengthened the trust capability further; the willingness to jointly start new initiatives and to speed up projects that got lost, developed with stronger intentions than ever before.

Regulators became more directly involved in the regional IS projects in Phases 3 and 4 . The regulators made the adjustment of rules to regional goals an internal issue in the project on 'modification of regulations for improving IE activities', although, this did not lead automatically to regulations that fit with area goals of waste exchange. A major problem remained that regulations are still developed with individual companies in mind, and consequently exchanges between them are treated as handling of waste.

\subsection{Conclusions on transformation/transition}

Although sustainability projects are the basis for reflexive regional learning processes at the Strategy Platform, the IS projects in the Rotterdam HIC are mainly balancing on the boundary of status quo and reform. Regional efficiency providing economic profits are the main incentives for companies to participate in the projects (see Figure 4).

Figure 4 Phases to sustainable development (see online version for colours)

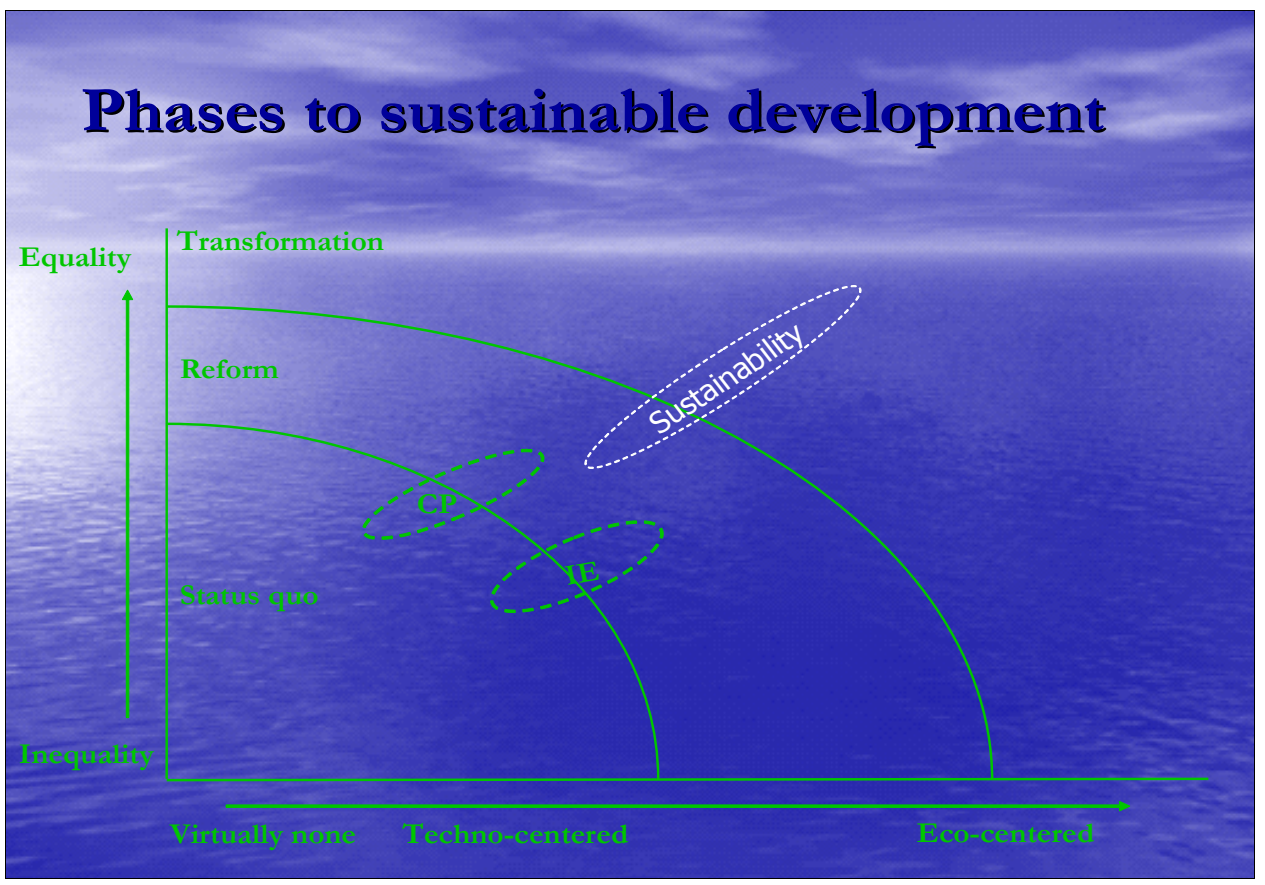


Loorbach (2007) states that to achieve success, the growing community of transition practitioners and researchers need to firmly ground transition management in existing disciplines and maximise the impact of transition management processes on regular policies. In essence, the strategic platform has an important position in this process, although, a real transformation to sustainability capabilities has still to take place.

\section{Final conclusions}

With respect to the described social science dimensions, we concluded separately that in case of:

- embeddedness - for many, positive embeddedness aspects is concluded that professional facilitation is necessary for the stimulation and monitoring of IS activities. The strategic platform built trust between the different strategic platform members representing government, industry, expertise centres, special task forces and an environmental advocacy organisation, on the basis of reflexive learning processes of sustainability projects in the region. The dynamic contributions of the relevant stakeholders had a key function in facilitating IS processes. Changes of cognitive, cultural and relational embeddedness issues have influenced this development.

- capabilities - technical, regulatory, trust and actualisation capabilities are present; however, the attention for social aspects and unlearning capabilities kept being limited. The dominant capabilities create a regional efficiency basis for IS in HIC.

- transformation - the concept of IS in the Rijnmond area is still regional efficiency-based, although some learning processes and sustainability aspects are beyond an emerging approach. The elaboration of sustainability approaches however, is still dominantly techno-centred.

The IS/Sustainability projects in the Rotterdam HIC show mainly the development of projects based on the principle of regional efficiency while after some time activities also show elements of regional learning (Baas and Boons, 2004). These elements include a broader scope of actors, more intensive relationships, an increase in the depth of issues and a more strategic vision that is developed for the system as a whole. At the same time, the trend remains based on projects with a strong efficiency orientation where the technical capability is dominant. The historical development of the regional partnerships has shaped preferences at the level of regional efficiency and related business profit requirements. On this manner it has generated a strong structural and cultural embeddedness that is difficult to change.

The combination of characteristics can be further understood if we look at the availability and use of capabilities by individual organisations within the region. Deltalinqs is a central actor throughout the period 1994-2002. Deltalinqs displayed and further developed substantial capabilities that were necessary for initiating regional efficiency projects and regional learning. Being a broker in a network comprised of governmental organisations, private firms and universities, it used these capabilities to stimulate other organisations in the network to develop similar capabilities. To some extent, this paid off, as firms and governmental organisations developed value and boundary capabilities, which were critical to further system development. However, not 
all organisations participated in this learning process. And, even the learning process was not unlearning in a radical way, moreover, a continued focus on efficiency was necessary to generate results that created and maintained legitimacy for further efforts, and formed a basis for developing trust among new participants in the network. Under the ROM-Rijnmond R3 programme from 2003, Deltalinqs transferred its coordinating responsibility to the $\mathrm{R} 3$ organisation. While remaining an important actor, Deltalinqs became part of a bigger system in which actors were able to further develop strategic sustainability projects that had the potential for breakthrough in the routines. At least the illustrations of the Heat Company and the HSF are illustrations for that.

Developments at the system level can only be understood through their emergence from actions of individual organisations. And the complex evolution of a sustainability region such as in the Rotterdam HIC shows that it is not individual organisations per se that hold the key to progress but rather their embeddedness in a receptive techno-, eco-, and socio-centred encouragement situation and their embodiment of crucial sustainability capabilities. Trust and communication issues have developed well; a joint regional sustainability approach still meets institutionalised routines that provide barriers to radical change processes. Especially the value and unlearning capabilities need better understanding as essential dimensions in sustainable region development.

\section{References}

Amit, R. and Schoemaker, P. (1993) 'Strategic assets and organizational rent', Strategic Management Journal, Vol. 14, pp.33-46.

Baas, L. and Boons, F. (2007) 'The introduction and dissemination of the industrial symbiosis projects in the Rotterdam harbour and industry complex', Int. J. Environmental Technology and Management, Vol. 7, Nos. 5-6, pp.551-577.

Baas, L.W. (1998) 'Cleaner production and industrial ecology, a Dutch experience', Journal of Cleaner Production, Vol. 6, Nos. 3-4, pp.189-197.

Baas, L.W. (2001) 'Developing an industrial ecosystem in Rotterdam: learning by ... what?', Journal of Industrial Ecology, Vol. 4, No. 2, pp.4-6.

Baas, L.W. (2002) Words and Actions: Evaluation Report INES Mainport Rotterdam 1999-2002 [in Dutch], Erasmus University, Rotterdam, December.

Baas, L.W. (2005) Cleaner Production and Industrial Ecology: Dynamic Aspects of the Introduction and Dissemination of New Concepts in Industrial Practice, Delft: Eburon.

Baas, L.W. and Boons, F.A. (2004) 'An industrial ecology project in practice: exploring the boundaries of decision-making levels in regional industrial systems', Journal of Cleaner Production, Vol. 12, Nos. 8-10, pp.1073-1085.

Barney, J. (1991) 'Firm resources and sustained competitive advantage', Journal of Management, Vol. 17, pp.99-120.

Boons, F. and Baas, L. (2006) 'Industrial symbiosis in a social science perspective', Discussion proposal for 3rd Industrial Symbiosis Research Symposium, Birmingham, UK, 5-6 August.

Boons, F.A. (2004) 'Connecting levels: a systems view on stakeholder dialogue for sustainability', Progress in Industrial Ecology, Vol. 1, No. 4, pp.385-396.

Boons, F.A.A. and Baas, L.W. (1995) 'The organisation of industrial ecology: the importance of regions', Proceedings 2nd European Roundtable on Cleaner Production, Rotterdam, 1-3 November.

Castells, M. (1996) The Rise of the Network Society (The Information Age: Economy, Society and Culture), Malden, MA: Blackwell Publishers, Inc., Vol. 1. 
Commission on Sustainable Development (2005) 'Changing unsustainable patterns of consumption and production; human settlements and water', Background Paper No. 4, United Nations Department of Economic and Social Affairs, Division of Sustainable Development, DESA/DPD/2005/4, New York, 11-22 April.

Dietz, J.L.G. (1992) 'Leerboek informatiekundige analyse (Education manual on information analysis)', Deventer.

Frosch, R.A. and Gallopoulos, N.E. (1989) 'Strategies for manufacturing', Special Issue: Managing Planet Earth, Scientific American, September, pp.144-152.

George, S. (1999) The Laguno Report, London: Pluto.

Gertler, N. (1995) 'Industrial ecosystems: developing sustainable industrial structures', Master thesis, MIT, Massachusetts.

Gnyawali, D.R. and Madhavan, R. (2001) 'Cooperative networks and competitive dynamics, a structural embeddedness perspective', Academy of Management Review, Vol. 26, No. 3, pp.431-445.

Granovetter, M. (1985) 'Economic action and social structure: the problem of embeddedness', American Journal of Sociology, Vol. 91, No. 3, pp.481-510.

Granovetter, M. (1992) 'Problems of explanation in economic sociology', in N. Nohra and R. Eccles (Eds.) Networks and Organizations: Structure, Form, and Action, Boston, MA: Harvard Business School Press.

Greiner, B. and Curtessi, G. (2005) The Happy Shrimp Farm, Rotterdam, October.

Harbison, J.R. and Pekar, P., Jr. (1998) Smart Alliances, San Francisco.

Hart, S. (1995) 'A natural-resource-based view of the firm', Academy of Management Review, Vol. 20, pp.986-1014.

Hopwood, B., Mellor, M. and O’Brien, G. (2005) 'Sustainable development: mapping different approaches', Sustainable Development, Vol. 13, pp.38-52.

Huy, Q.N. (2001) 'Time, temporal capability, and planned change', Academy of Management Review, Vol. 26, pp.601-624.

Jong, J. de (2006) 'Liberalising Dutch energy markets: champions and governance, rules and regulations: the 1995-2005 stories', Clingendael International Energy Programme, http://www.clingendael.nl/ciep.

Loorbach, D. (2007) Transition Management: New Mode of Governance for Sustainable Development, Utrecht: International Books.

Marx, K. (2004) 'The role of the social context for strategy-making: examining the impact of embeddedness on the performance of strategic initiatives', PhD thesis, Hochschule St. Gallen, Wiesbade, Deutscher Universitäts.

Morgan, G. (1980) 'Paradigms, metaphors, and puzzle solving in organization', Administrative Science Quarterly, pp.605-622.

Noorderhaven, N.G., Koen, C.I. and Beugelsdijk, S. (2002) 'Organizational culture and network embeddedness', CentER Discussion Paper 9, Tilburg University.

Nooteboom, B. (1999) 'The dynamic efficiency of networks', in A. Grandori (Ed.) Interfirm Networks: Organization and Industrial Competitiveness, London, pp.91-119.

Oerlemans, L.A.G., Meeus, M.T.H. and Boekema, F.W.M. (2000) 'On the spatial embeddedness of innovation networks: an exploration of the proximity effect', Paper presented at the 40th European Congress of the European Regional Science Association, Barcelona.

Rees, W. (1995) 'Achieving sustainability: reform or transformation?', Journal of Planning Literature, Vol. 9, pp.343-361.

ROM-Rijnmond (2003) To C or Not to C, Rotterdam.

ROM-Rijnmond (2006) R3 Project Overview, Rotterdam, June.

ROM-Rijnmond R3 (2006) 'Grand design: Warmte voor Zuidvleugel Randstad (heat for the southern part of Zuid-Holland)', Rotterdam, February. 
Russo, M. and Fouts, P. (1997) 'A resource-based perspective on corporate environmental performance and profitability', Academy of Management Journal, Vol. 40, pp.534-559.

Schneider, C.T. (2006) 'How can an industrial developer stimulate industrial ecology synergies in the acquisition of clients?', Master thesis, MSc Industrial Ecology, Delft/Leiden/Rotterdam, 17 August.

Senge, P., Kleiner, A., Roberts, C., Ross, R., Roth, G. and Smith, B. (1999) The Dance of Change: The Challenges of Sustaining Momentum in Learning Organizations, New York: Doubleday/Currency.

Silvester, S. (1997) 'Air-sharing, end report INES project phase 3a', Erasmus Studiecentrum voor Milieukunde, Rotterdam, 24 January.

Simsek, Z., Lubatkin, M. and Floyd, S. (2003) 'Interfirm networks and entrepreneurial behavior: a structural embeddedness perspective', Journal of Management, Vol. 29, pp.427-442.

Uzzi, B. (1997) 'Social structure and competition in interfirm networks: the paradox of embeddedness', Administrative Science Quarterly, Vol. 42, pp.35-67.

Vliet, F. van (1998) 'De Change Agent en zijn Resources: Een modelmatige benadering van regionale technologische veranderingsprocessen (The change agent and his resources: a model approach of regional technological change processes)', PhD thesis, Delft: Eburon.

Wallner, H.P. (1999) 'Towards sustainable development of industry: networking, complexity and eco-clusters', Journal of Cleaner Production, Vol. 7, No. 1, pp.49-58.

Wernerfelt, B. (1984) 'A resource-based view of the firm', Strategic Management Journal, Vol. 5, pp.171-180.

Weterings, R.A.P.M. (2000) 'Agroproductieparken - perspectieven en dilemma's', Rapportage in opdracht van Innovatie netwerk Groene ruimte en Agrocluster.

Zukin, S. and DiMaggio, P. (1990) 'Introduction', in S. Zukin and P. DiMaggio (Eds.) Structures of Capital: The Social Organisation of the Economy, Cambridge/New York: Cambridge University Press, pp.1-56.

\section{Notes}

1 The overview of organisational developments in the Rotterdam HIC is continuous but based on separate IE programmes; this section is a summary of the $\mathrm{PhD}$ analysis of Baas (2005).

2 A US MNC perceives the covenant as a risk for unexpected liabilities; they prefer to participate in separate projects of the covenant that are within the management policy of their organisation.

3 Voluntary agreements between the government and industry.

4 This is the part of the Hoogvliet/Rotterdam South river border delivery.

5 Natural gas is burned in greenhouses for heating and the input of $\mathrm{CO}_{2}$.

6 The picture of the Botlek Loop at the left under part of Figure 2 illustrates the waste heat exchange between companies, houses, greenhouses and an underground storage centre for cold and heat supply.

7 A worldview is an implicit or explicit view of reality (Morgan, 1980).

8 Some experts state that in the decision-making process for the unification of the European Union market, for which obstacles to the optimal operation of the free market had to be taken away, it was forgotten that from an economic perspective the free market does not always provide the best solution. Sometimes a monopoly works better, for instance in the case of the electricity supply. This is because with natural monopolies, the owner needs to have long-term investment perspectives. 